\title{
Green-synthesis of Silver Nanoparticles by Hygrophila auriculata Extract: Innovative Technique and Comprehensive Evaluation
}

\author{
Smita Nayak*, Priyanka Ghugare, Bhaskar Vaidhun \\ Department of Quality Assurance, Gahlot Institute of Pharmacy, University of Mumbai, Sector 14, Koparkhairane, \\ Navi Mumbai, Maharashtra, INDIA.
}

\begin{abstract}
Background: Metal nanoparticles are of great scientific interest as they bridge the gap between the bulk and atomic structures. A number of methods of synthesizing nanoparticles have been developed and can be grouped into top-down (physical), bottom-up (chemical) and biological methods. Physical methods are expensive due to continuous consumption of energy to maintain the high pressure and temperature employed in nanoparticle synthesis and requires highly sophisticated equipment. In the chemical synthesis of nanoparticles, generation of hazardous by-products as well as involvement of certain chemicals that are environmental contaminants is a major concern. As against this plant-mediated synthesis of nanoparticles employs green synthetic route, is clean, ecofriendly, cost effective, safe, convenient and beneficial technique for large-scale production of nanoparticles. Aim: The study focuses on green synthesis of silver nanoparticles using plant extract as reducing, capping and stabilizing agents. It has been reported that aqueous silver ions when exposed to plant leaf extract undergo reduction leading to formation of silver nanoparticles. Methods: In present study, silver nanoparticles were synthesized by using hydro alcoholic extract of Hygrophila auriculata whole plant as reducing agent. Results: Synthesis of silver nanoparticles was confirmed by UV spectroscopy, particle size analysis, zeta potential determination, Fourier Transform Infrared Resonance, X-Ray Diffraction, Scanning Electron Microscopy and Transmission Electron Microscopy. Conclusion: Plant mediated nanoparticle synthesis is a simple, reproducible and ecofriendly method for elucidation of silver nanoparticles. Data obtained reveals the role of hydro alcoholic extract of Hygrophila auriculata in silver nanoparticle synthesis.
\end{abstract}

Key words: Green synthesis, Silver nanoparticles, Hygrophila auriculata, Characterization, Surface Plasmon resonance.

\section{INTRODUCTION}

The term 'Nanotechnology' refers to fabrication, characterization, exploration and application of nanosized (1-100 $\mathrm{nm})$ materials in technological advances across diverse fields. It deals with the study of extremely minute structures and the prefix "nano" means "dwarf or miniature".

Nanotechnology provides the ability to engineer the properties of materials by controlling their size, thereby creating opportunity for exploitation of nanomaterials. ${ }^{2}$ Nanoparticles (NPs) have attracted attention for their positive impact in many sectors including consumer products, pharmaceuticals, cosmetics, transportation, energy and agriculture and are being increasingly produced for a wide range of newer applications within industry. ${ }^{3,4} \mathrm{~A}$ very interesting application of NPs in the scope of life sciences is their use as smart delivery systems. Metal NPs are of great scientific interest as they bridge the gap between the bulk and atomic structures. ${ }^{5} \mathrm{NPs}$ have unique physicochemical properties, i.e., high
Submission Date: 21-07-2020; Revision Date: 24-12-2020; Accepted Date: 03-05-2021

DOI: 10.5530/ijper.55.2s.122 Correspondence: Dr. Smita Nayak Professor and HOD, Department of Pharmaceutics, Gahlot Institute of Pharmacy, Koparkhairane,

Navi Mumbai-400709, Maharashtra, INDIA. Phone: +919869367410 Email id: smitanayak125@ yahoo.com

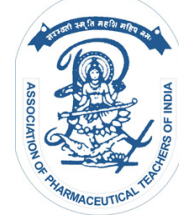

www.ijper.org 
surface area, high reactivity, tunable pore size and particle morphology. Recent advances in nanotechnology include the incorporation of metallic NPs into diverse industrial, medical and household products. ${ }^{6-8}$

Nanoparticles can be synthesized by top-down and bottom-up approach. ${ }^{9}$ Top-down refers to making nanoscale structures by various machining and etching techniques, whereas bottom-up or molecular nanotechnology, applies to building organic and inorganic structures atom-by-atom, or molecule-bymolecule (Figure 1). A number of physical and chemical approaches have been explored for the synthesis and stabilization of AgNPs. ${ }^{10}$ Physical method involves laser ablation and evaporation condensation methods whereas chemical method utilizes chemical reductants $\left(\mathrm{NaBH}_{4}\right.$, ethanol, ethylene glycol and so on), aerosol technique, electrochemical or sonochemical deposition, photochemical reduction and laser irradiation technique. ${ }^{11}$ Physical methods are expensive due to continuous consumption of energy to maintain the high pressure and temperature employed in NPs synthesis and requires highly sophisticated equipment. In the chemical synthesis of NPs, generation of hazardous byproducts and involvement of costly chemicals may lead to the adherence of noxious chemical entities to surface of NPs, which may adversely affect the environment and have far reaching consequences. ${ }^{12}$ As against this biological approach is close to principles of nature and mimics natural phenomenon that occur in biological systems. The current situation demands an ecofriendly, clean and economically viable way for the synthesis of NPs (Green nanotechnology). Among several biological methods of nanoparticle synthesis, microbe mediated synthesis of NPs is, yet not commercially viable as they involve maintenance of aseptic conditions and complex processes of maintaining cultures. ${ }^{13}$ An ecofriendly, clean, economically viable route of nanoparticles synthesis is the need of the hour. Plant based nanotechnology offers a suitable alternative to the physical, chemical and

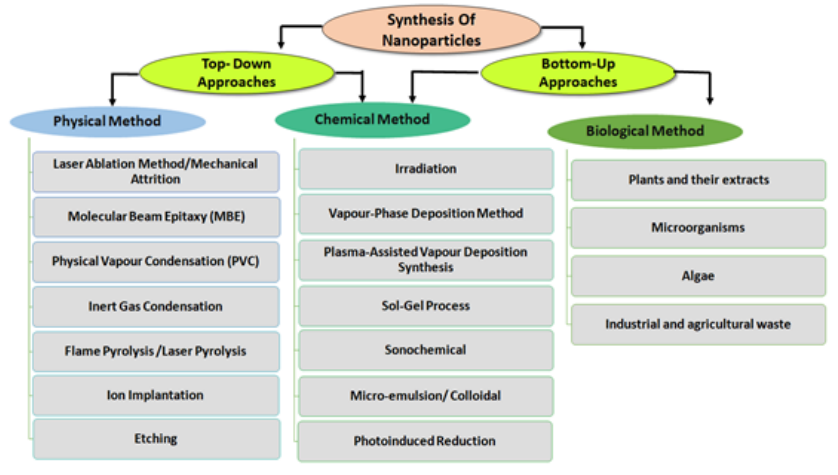

Figure 1: Approaches for Nanoparticles synthesis. microbiological methods discussed above. This paper outlines a method for synthesis of silver nanoparticles using plant extract as reducing, capping and stabilizing agent using a plant that hitherto has not been utilized for this purpose.

\section{Metallic Nanoparticles}

Nanoparticles from noble metals particularly silver, gold, gold-silver alloy, selenium, tellurium, platinum, palladium, silica, titania, zirconia, quantum dots, magnetite and uraninite have been studied extensively in recent times. Metallic nanoparticles differ in their physical and chemical properties such as photonics, catalysis, medical research and surface enhanced Raman spectroscopy as compared to the bulk materials. Several of these properties have important industrial applications and have been commercially exploited. ${ }^{14}$

\section{Silver Nanoparticles}

Amongst the noble metals, silver has been extensively used in treatment of infections. Silver exhibits catalytic, anti-bacterial activity, good conductivity and chemical stability. They also find application in field of optoelectronics as well as anti-bacterial agents in the health industry, food storage and textile industry. In addition, they have several environmental applications. ${ }^{15}$ Silver nanoparticles are reported to have anti-bacterial activity against Staphylococcus epidermidis, Pseudomonas aeruginosa, Staphylococcus aureus and E. coli. ${ }^{16}$ It was reported that Ocimum sanctum leaf extract could reduce silver ions into crystalline silver nanoparticles (size range 4-30 nm) within 8 min of reaction time. These NPs were stable due to the presence of proteins which may act as capping agents. O. sanctum leaves contain ascorbic acid which may play an important role in reduction of silver ions into metallic silver nanoparticles. These nanoparticles have shown strong anti-microbial activity against E. coli and S. aureus. ${ }^{17}$

Song and colleagues elucidated the fact that Pinus desiflora, Diospyros kaki, Ginko biloba, Magnolia kobus and Platanus orientalis leaf broths synthesized stable silver NPs with average particle size ranging from 15 to $500 \mathrm{~nm}$. In the case of $M$. kobus and D. kaki leaf broths, the synthesis rate and final conversion to silver NPs increased with increase in reaction temperature. Also, average particle size decreased from $50 \mathrm{~nm}$ to $16 \mathrm{~nm}$, when temperature was increased from $25^{\circ} \mathrm{C}$ to $95^{\circ} \mathrm{C}$. At the reaction temperature of $95^{\circ} \mathrm{C}$ more than $90 \%$ conversion was seen within eleven minutes using $M$. kobus leaf broth. ${ }^{18}$ As seen above, green chemistry has been used effectively for synthesis of silver nanoparticles. Plants are considered as green nanofactories in the genesis of 
nanoparticles. ${ }^{19}$ The major advantage of using plant extracts for biogenesis of silver nanoparticles is that they are easily available, safe and nontoxic, have plenty of metabolites that can contribute to the reduction of silver ions and are quicker than microbes in the synthesis. There is increasing interest in minimization of cost, time as well as waste and execution of sustainable procedures for the development of ecofriendly and simple methods for the synthesis of silver nanoparticles. ${ }^{20}$ In our study, hydro alcoholic extract of Hygrophila auriculata whole plant was explored in synthesis of silver nanoparticles.

\section{MATERIALS AND METHODS}

Fresh plant of Hygrophila auriculata (K. Schum) Heine (Figure 2) was collected in Kolhapur, India. The plant was authenticated at Department of botany, Ramnarain Ruia College, Matunga (E) Mumbai (Voucher Specimen no. HRL/AUTH/2019/1). Silver nitrate was procured from Sigma Aldrich. Other reagents used were of laboratory grade. Triple distilled water was used in the study.

\section{Preparation of extract}

Fully matured whole plant was used for extraction. Collected plant was thoroughly washed with tap water and further washed with distilled water, cut into fine pieces, dried at $40^{\circ} \mathrm{C}$ in oven for 7-8 days. The dried plant parts were coarsely powdered using hammer mill. Hydroalcoholic extract (1:1) was prepared using soxhlet assembly. The prepared extract was collected and dried on waterbath. The extract was stored at $4^{\circ} \mathrm{C}$ for further use.

\section{Synthesis of silver nanoparticles}

Plant extract $(15 \mathrm{ml})$ was added continuously to $100 \mathrm{ml}$ of 2 millimolar silver nitrate solution in triple distilled water with continuous stirring at $60^{\circ} \mathrm{C}$. Heating was stopped and stirring continued for $4 \mathrm{hr}$. The colour of

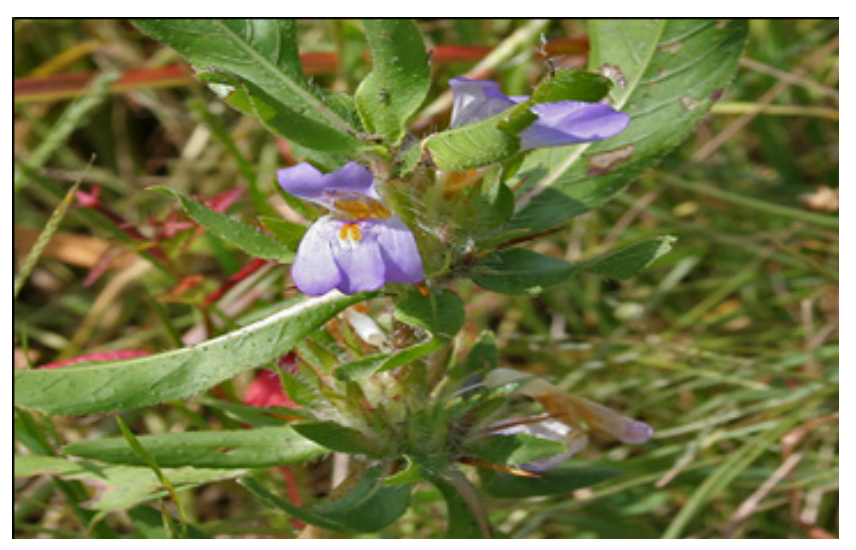

Figure 2: Hygrophila auriculata. the solution changed from colorless to yellow to brown indicating that silver nanoparticles were synthesized. Reaction mixture was centrifuged at $6000 \mathrm{rpm}$ for 15 min. The pellet was collected, rinsed thrice with triple distilled water and dried in hot air oven at $80^{\circ} \mathrm{C}$.

The resultant silver nanoparticles were characterized by UV spectroscopy, Particle size analysis, zeta potential determination, Fourier Transform Infrared Resonance, X-Ray Diffraction, Scanning Electron Microscopy and Transmission Electron Microscopy.

\section{UV-vis spectroscopy ${ }^{21}$}

This technique uses electromagnetic radiations between $190 \mathrm{~nm}$ to $800 \mathrm{~nm}$ and is divided into the ultraviolet (UV, 190-400 nm) and visible (VIS, 400-800 nm) regions. UV-vis spectroscopy is used for the detection of functional group, identification of unknown compounds and to determine purity of compound. As it is reported that silver nanoparticles exhibit Surface Plasmon Resonance phenomena, the extract was scanned in the range of 600 to $200 \mathrm{~nm}^{22-25}$

\section{Particle size analysis ${ }^{26}$}

Dynamic Light Scattering (DLS) system measures particle size, zeta potential and molecular weight from $0.3 \mathrm{~nm}$ to $8 \mu \mathrm{m}$. Particle size can be determined by measuring the random changes in the intensity of light scattered from a suspension or solution. Small particles in suspension undergo random thermal motion known as Brownian motion. Light from the laser light source illuminates the sample in the cell. The scattered light signal is collected with one of two detectors, either at a 90 degree (right angle) or 173 degree (back angle) scattering angle. For size measurement, prepared nanoparticles was dispersed in triple distilled water (1:50 ratio) and sonicated for 30 min. Then sample was introduced into the cuvettes. The sizes of nanoparticles were recorded.

\section{Zeta potential of synthesized nanoparticles ${ }^{27}$}

Zeta potential is a measure of the charge on a particle surface in a specific liquid medium. This value of surface charge is useful for understanding and predicting interactions between particles. Smaller particle sizes and higher surface charge (zeta potential) will typically improve stability of formulation. Zeta potential is measured using the technique of electrophoretic light scattering where particle motion is detected in an applied electric field. Synthesized silver nanoparticles were dispersed in water and zeta potential was measured.

\section{Scanning electron microscopy ${ }^{28}$}

Samples were thoroughly degassed and dried to eliminate any outgassing from organic contamination and water. 
Samples were cleaned ultrasonically using water and blown dry using a compressed gas. Powder sample was compressed into small disks for sample mounting.

Samples were attached to the flat plates using double-side carbon or copper tapes and observed under scanning electron microscope.

\section{Transmission electron microscopy ${ }^{29}$}

For the TEM characterization powder sample was dispersed in distilled water and ultrasonicated for $30 \mathrm{~min}$. One to two drops of sample were put on TEM grid and dried for $30 \mathrm{~min}$ and placed in TEM sample holder. The sample holder was placed in the transmission electron microscope for observation.

\section{$\mathrm{X}$ - ray diffraction $(\mathrm{XRD})^{30}$}

Silver nanoparticles were freeze dried for $12 \mathrm{hr}$. and then ground to fine powder. The sample was placed in sample holder and scanned.

\section{Fourier Transform Infrared Spectroscopy (FTIR) ${ }^{31}$}

The Sample was evaluated by using FTIR technique.

\section{RESULTS AND DISCUSSION}

\section{Characterization of silver nanoparticles}

Primary confirmation of synthesized silver nanoparticles can be observed visibly. Aqueous silver ions when exposed to plant leaf extract were reduced and resulted in a color change from colorless (Figure 3(a)) to yellowish

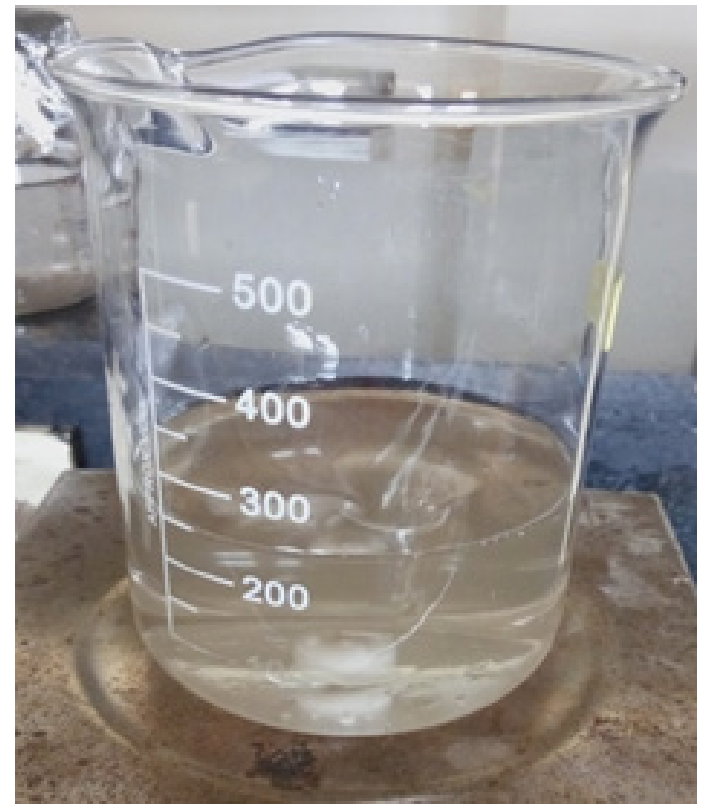

Figure 3(a): Silver nitrate solution + extract of Hygrophila auriculata- initial sample. brown to brown (Figure 3(b)) indicating the formation of silver nanoparticles.

\section{UV-Vis Spectroscopy}

The primary synthesis of silver nanoparticles was monitored with color change and UV-Vis spectroscopy. Aqueous silver ions when exposed to plant leaf extract were reduced and resulted in a color change from colorless to yellowish to brown indicating the formation of silver nanoparticles. The synthesis of the silver nanoparticles in aqueous solution was confirmed by recording the absorption spectra at a wavelength range of 200-600 nm (Figure 4). Synthesized silver nanoparticles exhibited Surface Plasmon Resonance phenomenon with absorption maxima at $422 \mathrm{~nm}$. This is in line with the observations of several other researchers who have carried out studies on surface Plasmon resonance phenomena exhibited by silver nanoparticles. ${ }^{32-35}$

\section{Particle Size Analysis}

The average size of the particles and polydispersity index (PDI) of the synthesized silver nano particles were determined by particle size analyzer and the results are shown in Figure 5. Data shows the average particle diameter is $313.8 \mathrm{~nm}$ and Polydispersity index is 0.481 indicating that the particle size distribution is narrow.

\section{Zeta potential of synthesized nanoparticles}

Zeta potential, an indicator of surface charge on the silver particles gives idea of particle stability in formulation. Results indicate that synthesized silver nanoparticles had zeta potential value of $-10.8 \mathrm{mV}$ (Figure 6). This indicates

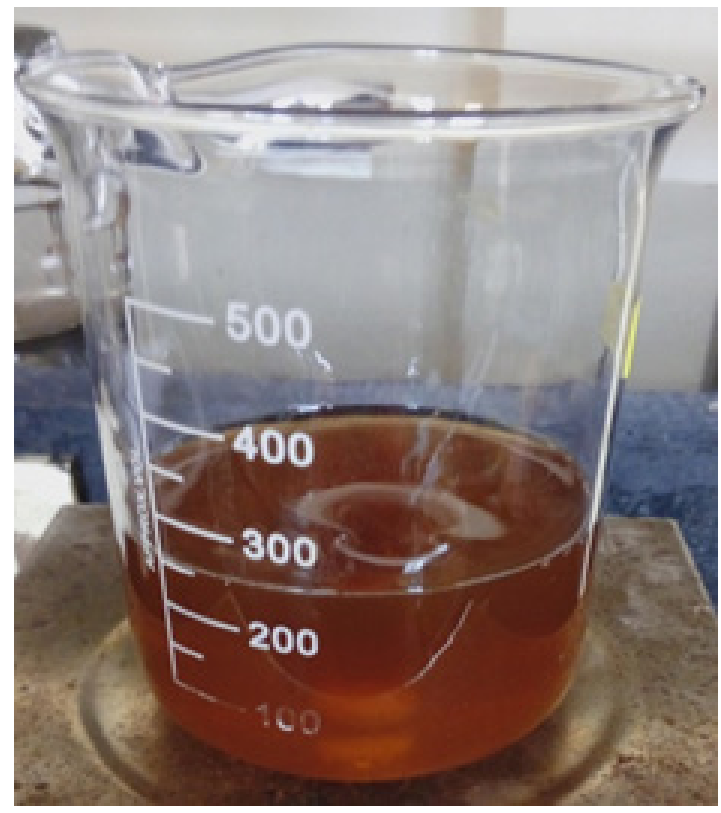

Figure 3(b): Silver nanoparticles in suspension seen $4 \mathrm{hr}$. after stirring. 


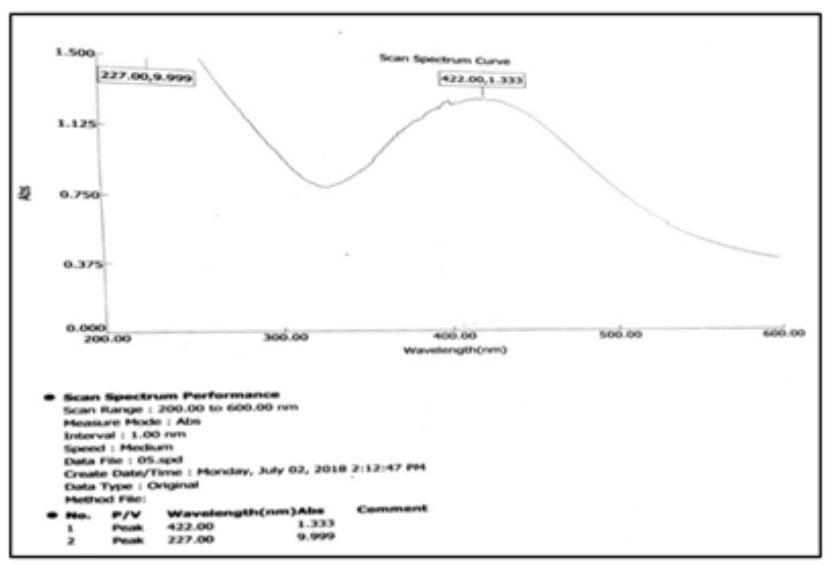

Figure 4: Surface Plasmon Resonance exhibited by silver nanoparticles.

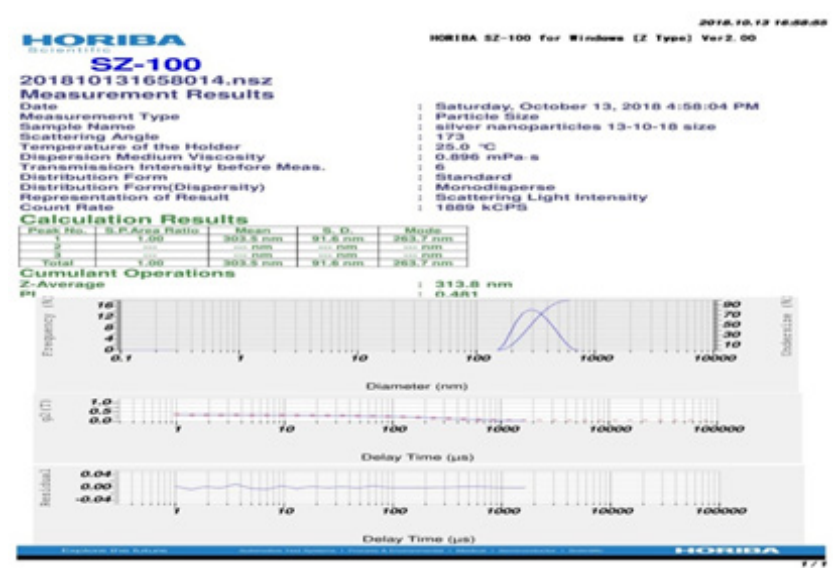

Figure 5: Particle size analysis of silver nanoparticles.

that the surface of synthesized silver nanoparticles is negatively charged and proves that the particles will be stable in solution due to repulsive forces.

\section{Scanning Electron Microscopy}

As seen in this micrograph (Figure 7), spherical nanoparticles in the size range $140 \mathrm{~nm}-300 \mathrm{~nm}$ were observed. Aggregation of particles was not seen indicating that silver nanoparticles have surface charge and were stabilized by plant based capping agent. ${ }^{28}$

\section{Transmission electron microscopy}

The shape and size of the resultant particles were elucidated with the help of transmission electron micrography. The TEM micrographs suggest that the size of the particles was less than $100 \mathrm{~nm}$ (Figure 8). The particles were spherical in shape and smooth in appearance.

\section{X- ray diffraction (XRD)}

Four intense peaks characteristic for silver nanoparticles were observed at $38.08^{\circ}, 46.19^{\circ}, 64.5^{\circ}$ and $77.4^{\circ}$

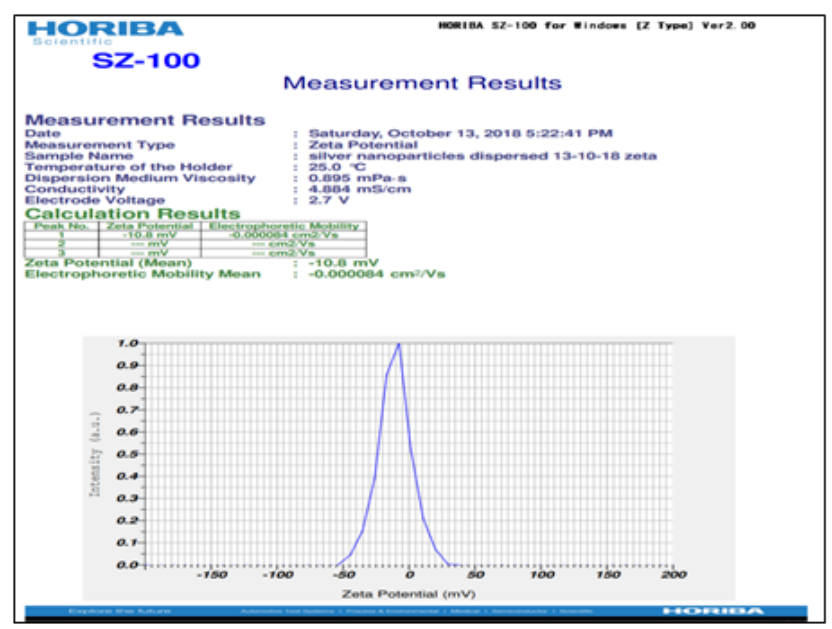

Figure 6: Zeta Potential of nanoparticles.
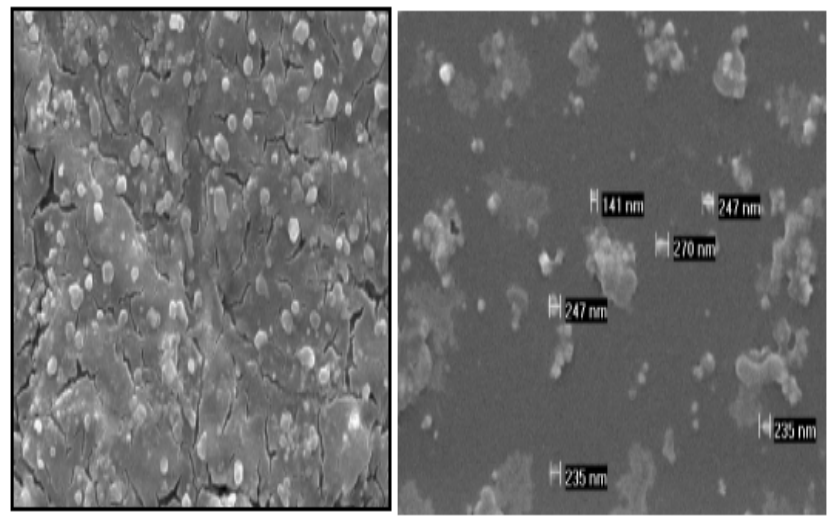

Figure 7: SEM of Silver Nanoparticles.

corresponding to the (111), (200), (220) and (311) planes respectively (Figure 9). ${ }^{29}$ The XRD pattern also showed two additional intense peaks of bio-organic phase present on the surface of the silver nanoparticles. These peaks being weaker than the silver peaks $\left(27.2^{\circ}\right.$ and $\left.32.9^{\circ}\right)$ may be attributed to presence of bio-organic compounds on surface of silver nanoparticles. Other studies prove ample proof of presence of phytoconstituents on surface of nanoparticles when they are synthesized by green route. ${ }^{32-34}$

\section{FTIR of synthesized nanoparticles}

The role of phytoconstituents as reducing, capping and stabilizing agents can be confirmed by assessing presence of functional groups on the surface of silver NPs synthesized by green chemistry route. FTIR analysis of the sample revealed presence of peaks at 3562.64, 2916.47, 2848.96, 2465.1, 1516.1, 1026.16 and 420.5 $\mathrm{cm}^{-1}$ (Figure 10). Stretching between 3200 to $2700 \mathrm{~cm}^{-1}$ can be attributed to presence of carbon and hydrogen containing species including amines, amine salts, alkanes, alkenes and carboxylic acids. Other functional groups 


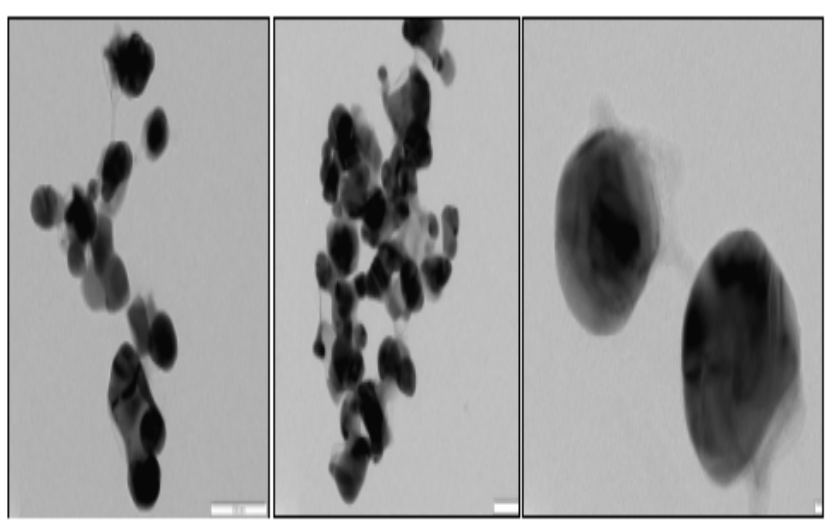

Figure 8: TEM of Silver Nanoparticles.

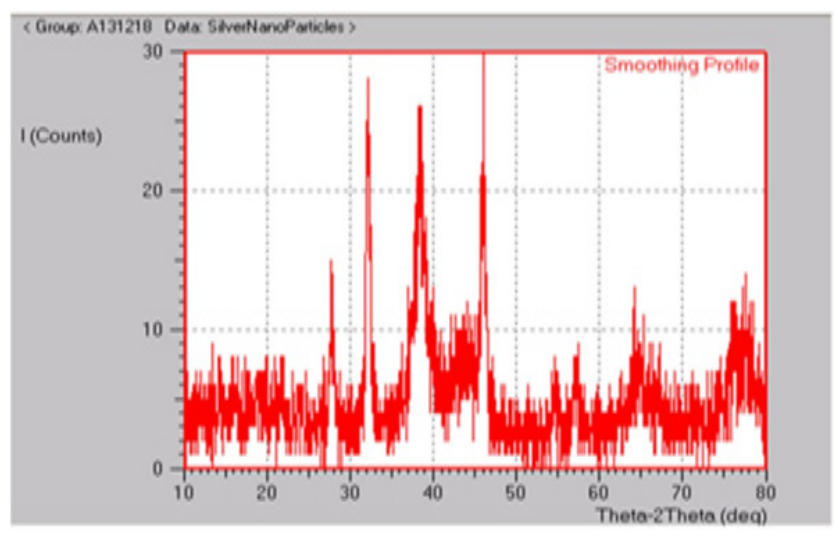

Figure 9: XRD of Silver Nanoparticles.

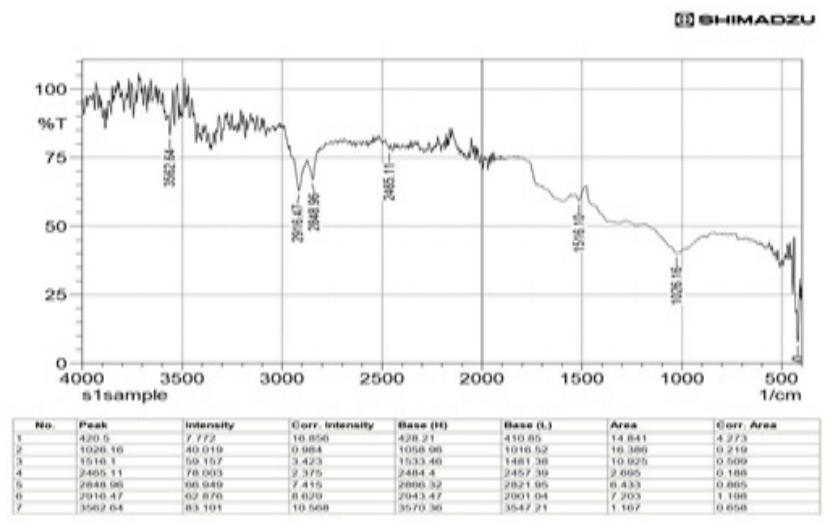

Figure 10: FTIR of Silver Nanoparticles.

that may be present include anhydrides, esters, ethers, alcohols and phenols (attributed to peak at 1026.16 $\left.\mathrm{cm}^{-1}\right)$. Other weak bands are indicative of nitrites, aromatic rings and aldehydes. Thus, FTIR analysis of the sample conclusively established the presence of organic molecules including carboxyl, hydroxyl and amino groups on the surface of silver NPs leading to the inference that phytoconstituents from plants contribute to not only synthesis but also stabilization of NPs. ${ }^{30,31}$

\section{CONCLUSION}

There is abundant proof of the role of plant extracts as bio-reductive agents in synthesis of silver nanoparticles. Also, considerable studies have been carried out on silver NPs elucidating their role as promising antimicrobial, antibacterial, antioxidant, anticancer agents. ${ }^{36-42}$ In the current study, hydro alcoholic extract of Hygrophila auriculata whole plant successfully reduced silver ions to silver nanoparticles with minimum utilization of reactants and energy. The primary indicator of completion of reduction of silver ions is change in color from colorless to yellowish brown to brown. In this study, the synthesized NPs were evaluated and confirmed to be in nanometric size range, having surface charge attributable to adhering functional groups of plant origin. In addition, presence of biomolecules on their surface was established by FTIR. Minimal aggregation of particles was confirmed by SEM and TEM analysis indicating that the procedure employed for synthesis was also contributing to capping and stabilization. Further these particles were spherical in shape hinting at maximal surface area as well as enhanced anti-microbial activity. The current study contributes to the body of knowledge regarding AgNPs and provides a simple reproducible technique of silver NP synthesis. In conclusion, the huge biodiversity of India is home to vast untapped natural resources that can be exploited for the benefit of mankind in more ways than one.

\section{ACKNOWLEDGEMENT}

The authors thank the Management of Gahlot Institute of Pharmacy for providing support for carrying out the research work. The authors also thank University of Mumbai for funding this project.

\section{CONFLICT OF INTEREST}

The authors declare no conflict of interest.

\section{ABBREVIATIONS}

Nm: Nanometers; NPs: Nanoparticles; AgNPs: Silver nanoparticles; $\mathbf{N a B H}_{4}$ : Sodium borohydride; DLS: Dynamic light scattering; TEM: Transmission electron microscopy; FTIR: Fourier transform infrared; XRD: $\mathrm{X}$ - ray diffraction.

\section{REFERENCES}

1. Shapira P, Youtie J. Introduction to the symposium issue: Nanotechnology innovation and policy-current strategies and future trajectories. J Technol Transf. 2001;36(6):581-6. 
2. Mobasser S, Firoozi AA. Review of nanotechnology applications in science and engineering. J Civil Eng Urban. 2016;6(4):84-93.

3. Ahmed S, Ahmad M, Swami BL, Ikram S. A review on plants extract mediated synthesis of silver nanoparticles for antimicrobial applications: A green expertise. J Adv Res. 2016;7(1):17-28.

4. Baalousha M, Lead JR. Overview of nanoscience in the environment. Environmental and human health impacts of nanotechnology. Blackwell Publishing Ltd. 2009;1-29.

5. Buffat $P$, Borel JP. Size effect on the melting temperature of gold particles. Phys Rev A. 1976;13(6):2287-98.

6. Aherne D, Ledwith D, Gara M, Kelly JM. Optical properties and growth aspects of silver nanoprisms produced by a highly reproducible and rapid synthesis at room temperature. Adv Func Mater. 2008;18(14):2005-16.

7. Zhang W, Qiao X, Chen J. Synthesis of silver nanoparticles-effects of concerned parameters in water/oil microemulsion. Mater Sci Eng B. 2007;142(1):1-15.

8. Lee PC, Meisel D. Adsorption and surface enhanced raman of dyes on silver and gold sols. J Phys Chem. 1982;86(17):3391-95.

9. Kalpana VN, Rajeswari VD. A review on green synthesis, biomedical applications and toxicity studies of ZnO NPs. Bioinorg Chem Appl. 2018;1-12.

10. Lee $\mathrm{SH}$, Jun $\mathrm{BH}$. Silver nanoparticles: Synthesis and application for nanomedicine. Int J Mol Sci. 2019;20(4):865-73.

11. Brito-Silva AM, Gómez LA, Araújo CB, Galembeck A. Laser ablated silver nanoparticles with nearly the same size in different carrier media. $J$ Nanomater. 2010;2010:1-7.

12. Ali A, Zafar H, Zia M, ulHaq I, Phull AR, Ali JS, et al. Synthesis, characterization, applications and challenges of iron oxide nanoparticles. Nanotechnol Sci Appl. 2016;9:49-67.

13. Velusamy P, Kumar GV, Jeyanthi V, Das J, Pachaiappan R. Bio-inspired green nanoparticles: Synthesis, mechanism and antibacterial application. Toxicol Res. 2016;32(2);95-102.

14. Jeevanandam J, Barhoum A, Chan YS, Dufresne A, Danquah MK. Review on nanoparticles and nanostructured materials: History, sources, toxicity and regulations. Beilstein J Nanotechnol. 2018;9(1):1050-74.

15. Khan I, Saeed K, Khan I. Nanoparticles: Properties, applications and toxicities. Arab J Chem. 2019;12(7):908-31.

16. Nakamura S, Sato M, Sato Y, Ando N, Takayama T, Fujita M, et al. Synthesis and application of silver nanoparticles (Ag NPs) for the prevention of infection in healthcare workers. Int J Mol Sci. 2019;20(15):3620-35.

17. Sharma G, Bhavesh R, Kasariya K, Sharma AR, Singh RP. Biosynthesis of silver nanoparticles using Ocimum sanctum (Tulsi) leaf extract and screening its antimicrobial activity. J Nanopart Res. 2011;13(7):2981-8.

18. Song JY, Kim BS. Rapid biological synthesis of silver nanoparticles using plant leaf extracts. Bioprocess Biosyst Eng. 2009;32(1):79-84.

19. Ahmad S, Munir S, Zeb N, Ullah A, Khan B, Ali J, et al. Green nanotechnology: A review on green synthesis of silver nanoparticles an eco-friendly approach. Int J Nanomed. 2019;14:5087-107.

20. Chaudhari SP, Damahe A, Kumbhar P. Silver nanoparticles: A review with focus on green synthesis. Int J Pharm Res Rev. 2016;5(3):14-28.

21. Shah RS, Shah RR, Pawar RB, Gayakar PP. UV-visible spectroscopy: A review. Intl J Inst Pharm Life Sci. 2015;5(5):491-4.

22. Devaraj P, Kumari P, Chirom A, Renganathan A. Synthesis and characterization of silver nanoparticles using cannonball leaves and their cytotoxic activity against MCF-7 cell line. J Nanotechnol. 2013;1-5.

23. Anandlakshmi K, Venugobal J, Ramaswamy V. Characterization of silver nanoparticles by green synthesis method using Pedalium murex leaf extract and their antibacterial activity. Appl Nanosci. 2016;6(3):399-408.

24. Zhang XF, Liu ZG, Shen W, Gurunathan S. Silver nanoparticles: Synthesis, characterization, properties, applications and therapeutic approaches. Int J Mol Sci. 2016;17(9):1534-68.
25. Aritonang $\mathrm{H}$, Koleangan $\mathrm{H}$, Wuntu $\mathrm{A}$. Synthesis of silver nanoparticles using aqueous extract of medicinal plants (Impatiens balsamina and Lantana camara) fresh leaves and analysis of antimicrobial activity. Int $\mathrm{J}$ Food Microbiol. 2019;2019(1):1-8.

26. Bar H, Bhui DK, Sahoo GP, Sarkar P, Pyne S, Misra A. Green synthesis of silver nanoparticles using seed extract of Jatropha curcas. Colloids Surf A Physicochem Eng Asp. 2009;339(1-3):134-9.

27. Vigneshwaran N, Nachane RP, Balasubramanya RH, Varadarajan PV. A novel one-pot 'green' synthesis of stable silver nanoparticles using soluble starch. Carbohydr Res. 2006;341(12):2012-8.

28. Sivakumar SR, Sridhar V, Abdul K. Antioxidant, antimicrobial and sewage treatment of synthesised silver nanoparticles from leaf extract of Hygrophila auriculata (schumsch) heine. Indo Am J Pharm Res. 2017;4(08):2350-61.

29. Salve SD, Bhuktar AS. Pharmacognosy and phytochemical evaluation of Hygrophila auriculata (Schumach.) Heine. root. J Phytopharm. 2017;6(4):2106.

30. Kshirsagar AD, Ingale KG, Vyawahare NS, Thorve VS. Hygrophila spinosa: A comprehensive review. Pharmacogn Rev. 2010;4(8):167-71.

31. Gurdeep R, Chatwal S, Sham A. In: Instrumental Methods of Chemical Analysis. $5^{\text {th }}$ ed: Himalaya Publishing House. 2009;2.55-63.

32. Smitha SL, Nissamudeen KM, Philip D, Gopachandran KG. Studies on surface Plasmon resonance and photoluminescence of silver nanoparticles. Spectrochim Acta A Mol Biomol Spectrosc. 2008;71(1):186-90.

33. Gopinath V, Mubarak AD, Priyadarshini S, Priyadharsshini NM, Thajuddin N, Velusamy P. Biosynthesis of silver nanoparticles from Tribulus terrestris and antimicrobial activity: A novel biological approach. Colloids Surf B Biointerfaces. 2012;96:69-74.

34. Basavegowda N, Idhayadhulla A, Lee YR. Preparation of Au and Ag nanoparticles using Artemisia annua and their in vitro antibacterial and tyrosinase inhibitory activities. Mater Sci Eng C Mater Biol Appl. 2014;43:5664.

35. Bindhu MR, Umadevi M. Synthesis of monodispersed silver nanoparticles using Hibiscus Cannabinus leaf extract and its antimicrobial activity. Spectrochim Acta A Mol Biomol Spectrosc. 2013;101:184-90.

36. Kadam SD, Shinde SP, Chavan TS, Phatake YB, Mane SG, Dhawan SS, et al. Green synthesis of silver nanoparticles by using stem, leaves and fruits extracts of umber (Ficus racemosa). Int J Pharm Investig. 2020;10(3):312-9.

37. Sumitha S, Vasanthi S, Shalini S, Chinni SV, Gopinath SC, Kathiresan S, et al. Durio zibethinus rind extract mediated green synthesis of silver nanoparticles: Characterization and biomedical applications. Phcog Mag. 2019;15(60):52-8.

38. Krishnakumar K, Dineshkumar B, Punathil RR. Green synthesis of silver nanoparticles using Hydnocarpus pentandra leaf extract: In-vitro cyto-toxicity studies against Mcf 7 cell line. J Young Pharm. 2018;10(1):16-9.

39. Sreeharsha N, Kathiravan G, Rajagopal K, Rajasekar A, Rajangam B, Aldhubiab BE, et al. Synthesis, characterization, and biological activity of silver nanoparticles synthesized from Aristolochia bracteolata Lam. Phcog Mag. 2020;16(71):568-73.

40. Mameneh R, Shafiei M, Aidy A, Karimi E, Badakhsh B, Abbasi N. Toxicity study of silver nanoparticles synthesized from aqueous flower extract of Scrophularia striata on MCF-7 human breast cancer cell line. Phcog Mag 2019;15(60):66-72.

41. Bose P, Pattanayak SP, Priyam A. Herniarin, a natural coumarin loaded novel targeted plasmonic silver nanoparticles for light activated chemophotothermal therapy in preclinical model of breast cancer. Phcog Mag. 2020;16(5):S474-85.

42. Rathna K, Navyaka P, Haque E. Bioengineered Silver Nanoparticle from Spirulina platensis in attenuating biofilm mediated virulence in Vibrio parahemolyticus: An in vitro and in vivo Approach. Int J Pharm Investigation. 2020;10(4):486-91. 
PICTORIAL ABSTRACT

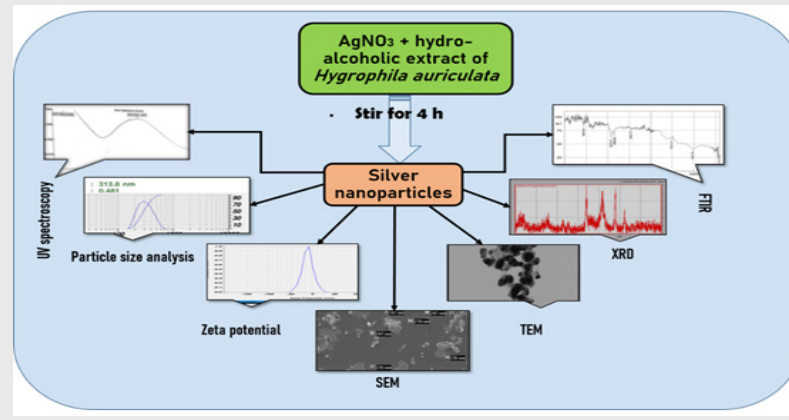

About Authors

\section{SUMMARY}

In the current study, silver nitrate was reduced by reacting with hydro alcoholic extract of Hygrophila auriculata via an environmentally friendly, phytoreductive approach. Surface plasmon resonance phenomenon elicited by silver nanoparticles was used to monitor the reaction and optimize the process. The resulting nanoparticles were characterized by UV spectroscopy, particle size analysis, zeta potential determination, Fourier Transform Infrared Resonance, $X$-Ray Diffraction, Scanning Electron Microscopy and Transmission Electron Microscopy. The results obtained support the hypothesis that plant-based nanotechnology provides an ecofriendly and economically viable route for synthesis of silver nanoparticles.

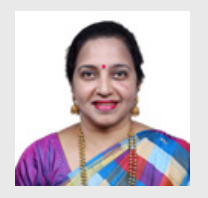

Smita Nayak is working as Professor and HOD, Department of Pharmaceutics in Gahlot Institute of Pharmacy, Koparkhairane. She has previously worked in FDC Limited and Piramal Healthcare Ltd in the departments of Quality Assurance and Formulation Development. She has guided more than $12 \mathrm{M}$. Pharm students. She is reviewer for national and international journals and has presented posters at national and international conferences. She has more than 40 publications to her credit. Her areas of interest include solid dispersions, rectal drug delivery systems, gastric drug delivery systems, colon drug delivery systems, controlled drug delivery systems, nanoparticulate drug delivery systems, analytical method development and validation, isolation and biological activity of phytochemicals and herbal formulation development. She is a member of several professional bodies including IPA-MSB, CRS-IC, APTI, IAOCP, SPDS.

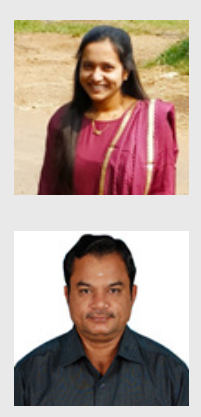

Priyanka Ghugare has completed her M. Pharm in Quality Assurance and is working as R\&D officer in Milan Laboratories, India. She has published two review articles in journals of repute. She has presented different posters during her M. Pharm studies.

Bhaskar Vaidhun is currently working as the Principal at Gahlot Institute of Pharmacy, Navi Mumbai, Maharashtra. He has more than 34 years of teaching and research experience. He has guided 13 post-graduate students and guided 11 research scholars under his supervision. He has published $100+$ research papers in the journals of repute. He has presented several papers in national as well as international conferences. He is a life member of IPA, APTI, IPGA, IHPA, etc.

Cite this article: Nayak S, Ghugare P, Vaidhun B. Green-synthesis of Silver Nanoparticles by Hygrophila auriculata Extract: Innovative Technique and Comprehensive Evaluation. Indian J of Pharmaceutical Education and Research. $2021 ; 55(2 s): s 510-s 517$. 